\title{
Histopathologic Study of Human Microsporidia Inespecificity (Protozoa, Microspora) with Visceral Dissemination in Another Vertebrates Hosts.
}

\author{
Arcay, L.*, Bruzual, E.**, Baez Abreu de Borges, E.*** and Finol, H.J**** \\ *Instituto Zoologia Tropical, Fac. Ciencias Univ.Central Venezuela.Caracas 1041-A \\ **Escuela Medicina J.M. Vargas, Fac. Medicina, U C V, Caracas \\ ***Facultad de Medicina, Universidad Central de Venezuela, Caracas \\ *****Centro Microscopia Electrónica, Fac. Ciencias, Univ. Central Venezuela
}

Microsporidia are obligate intracellular protozoan parasites infecting a broad range of vertebrates and invertebrates which belonging to the Phylum Microspora. They are eukaryotes and the transmittable stage beging as a resistent spore which is usually small, posseses a thick wall and contains a characteristic polar tube apparatus, which serves to transmit the sporoplasm of the spore to the hospedador cell. These Phylum Microspora consists of approximately 150 genera and over 1000 species, of which 13 are present known to infect humans, but were not routinely recogniezed as pathogens in humans until the AIDS pandemic in the $1980 \mathrm{~s}$.

In Venezuela we have studied patients immunocompetents and immunodephicients (HIV +), especially of several age and communities of diferents socio-economic positions with diarreic syndromes, originated by Enterocytozoon bieneusi and Encephalitozoon (Septata) intestinalis

These species that infect humans, demonstrated a great amount variability as a host range. We have made experimental infections in laboratory rodents (mice, rats, hamsters,guineapig), ducks, toads and tadpoles, in which we have demonstrated the "host inespecificity" and the "visceral dissemination" histopathologically in the intestine, liver, biliar vessel, pancreas, spleen, pulmon, brain, heart, kidney, thiroids and suprarenal glands. In toads we have obtained infection also in the testes and in the cloaca.

In the histologic diagnosis we have used formalin-fixed and paraffin embeded tissues. In staining tissues and in feces, we have used Kinyoun according to the acid resistance of the Microsporidia, taking a typical fucsia-red color. In the Microscopic study we have used a Leitz Microscope - Orthoplan Model with $1250 \mathrm{X}$ and a Photographical Camera Wild MPS 51 Model.

\footnotetext{
* larcay@strix.ciens.ucv.ve
} 


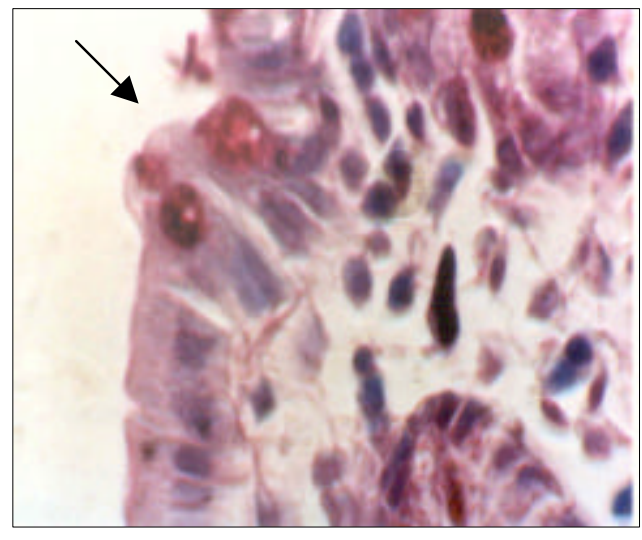

Fig. 1. Hamster I3 - Plasmodio of Microspora in the intestinal epitelium. Kinyoun $+.1250 \mathrm{X}$

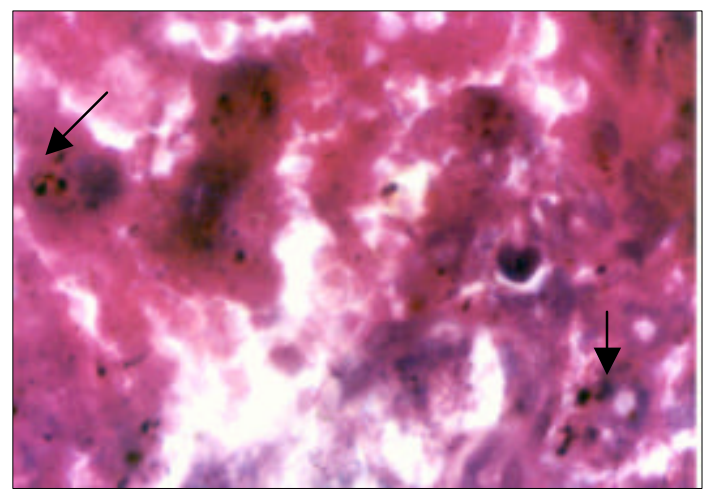

Fig. 3. Hamster - Liver: Desorganized hepatocytes and tisular lisis. Microspora scattered.

Kinyoun $+.1250 \mathrm{X}$

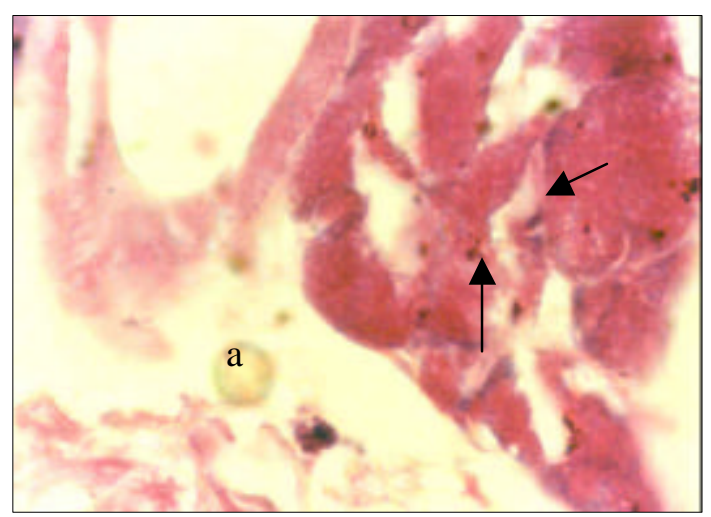

Fig. 5. Rat - Thymus: Scattered Microspora in the tissue. $(\mathrm{a}=$ artefact $)$ Kinyoun + . $1250 \mathrm{X}$

*larcay@strix.ciens.ucv.ve

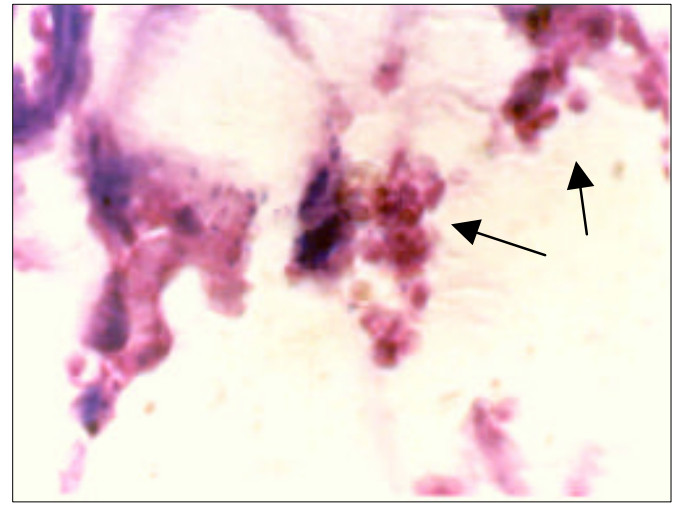

Fig. 2. Hamster - Rectum: Free Microsporidia. Kinyoun $+.1250 \mathrm{X}$

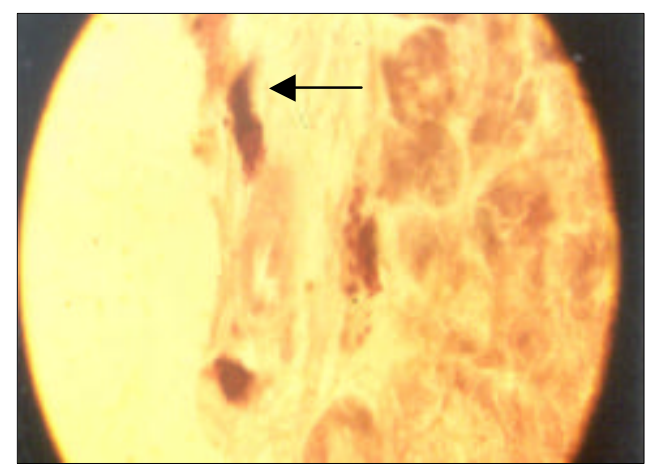

Fig. 4. Hamster - Pancreas: Accumulus of Microspora in adjuvant conjunctive. Kinyoun $+.1250 \mathrm{X}$

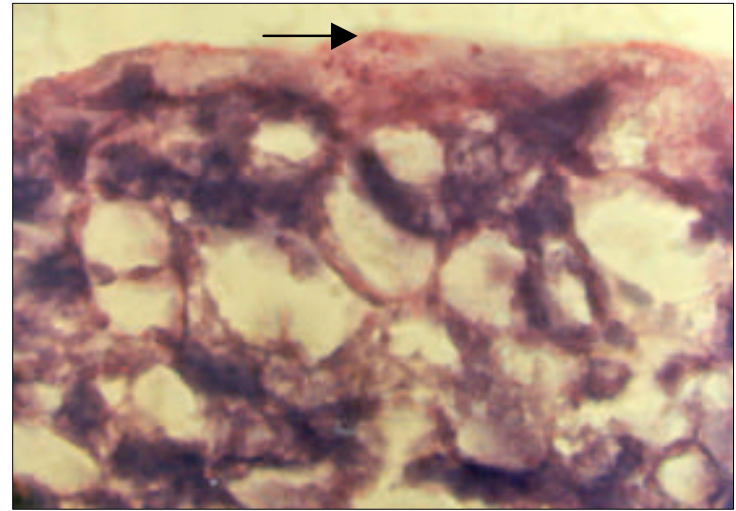

Fig. 6. Duck - Suprarenal gland: Microspora clustered in the capsule of the gland. Kinyoun $+.1250 \mathrm{X}$ 